\title{
Potassium Transport in Non-growing Mycelium of Neocosmospora vasinfecta
}

\author{
By K. BUDD \\ Department of Biology, Queen's University, Kingston, Ontario, Canada
}

(Accepted for publication 28 August 1969)

\begin{abstract}
SUMMARY
Mycelium of potassium-limited Neocosmospora vasinfecta had a lowered potassium content and an increased sodium content compared with mycelium grown in presence of excess potassium and no sodium. Potassium uptake involves the exchange for $\mathrm{Na}^{+}$and probably also for $\mathrm{H}^{+}$.

Total potassium uptake was decreased to half by a fivefold equivalent excess of rubidium, but was essentially unaffected by a Ioo-fold equivalent excess of sodium. Calcium and magnesium had intermediate effects. Potassium uptake was inhibited by sodium azide (mM) and by dinitrophenol $(0.3 \mathrm{~mm})$. These depressed the equilibrium potassium level but had a much smaller effect on the time required to reach equilibrium. Loss of potassium by $\mathrm{K}^{+}$-loaded mycelium to sodium azide or dinitrophenol solutions or to water was small. Much greater losses occurred to solutions of rubidium but not of sodium.

It is suggested that the equilibrium potassium level is determined only in part by exchange-diffusion at the mycelium surface, and that net potassium uptake is a metabolic process.
\end{abstract}

\section{INTRODUCTION}

Studies of the transport of inorganic ions by mycelial fungi are scarce. The only fungus which has been systematically studied from this point of view is the yeast, Saccharomyces cerevisiae (Rothstein, 1965). Although some of the major features of ion transport in this fungus are now clear, it seems impossible to decide whether yeast is representative of the fungi as a group in this respect.

In the absence of growth, net movements of ions between the cells and the environmental fluid can be observed, under suitable conditions, with yeasts and other microorganisms. The use of non-growing organisms is an advantage, since it simplifies interpretation of the relationship of metabolism to the transport processes, and allows the latter to be studied in relatively simple experimental solutions. In preliminary experiments, mycelium of Neocosmospora vasinfecta grown in a medium of high (I06 m-equiv./1.) potassium content (Budd, I969a) was harvested in mid-logarithmic phase and transferred to solutions of potassium salts lacking a nitrogen source. In such solutions, growth as defined by net protein increase was not measurable. Net uptake of potassium by this mycelium was small and variable. Replacement of most of the $\mathrm{K}^{+}$of the growth medium by $\mathrm{Na}^{+}$produced a mycelium of relatively low $\mathrm{K}^{+}$ content when harvested in late logarithmic phase. Some of the characteristics of potassium transport by this low-potassium mycelium are reported in this communication. A preliminary report of this work has already been published (Budd, I969 $b$ ). 


\section{METHODS}

Neocosmospora vasinfecta ATCC I 1686 (American Type Culture Collection, Rockville, Md., U.S.A.) was grown in liquid shaken cultures from standardized mycelial inocula for 46 to $50 \mathrm{hr}$ at $25 \pm 0.5^{\circ}$. The culture medium was a low- $\mathrm{K}^{+}$variant of the medium Gl previously described by Budd (I969a) and contained (per 1. glass-distilled water): glucose, 30.0 g.; $\mathrm{NaNO}_{3}, 8 \cdot 5$ g.; $\mathrm{MgSO}_{4} \cdot 7 \mathrm{H}_{2} \mathrm{O}, 2.5$ g.; $\mathrm{KH}_{2} \mathrm{PO}_{4}$, 0.10 g.; $\mathrm{NaH}_{2} \mathrm{PO}_{4}$. $\mathrm{H}_{2} \mathrm{O}, 0.90 \mathrm{~g}$.; trace elements according to Horowitz \& Beadle (I943); $\mathrm{pH}$ before autoclaving, 4.5. Analysis showed the $\mathrm{K}^{+}$and $\mathrm{Na}^{+}$contents of this medium to be 0.7 and I06.8 m-equiv./1. respectively, in contrast to I06.0 m-equiv./1., and essentially zero for medium Gl. Growth on the low-K+ medium was logarithmic from the time of inoculation to the 56 th $\mathrm{hr}$ of incubation. The mycelium was separated by filtration, washed by suspension in distilled water, and samples of 30 to $50 \mathrm{mg}$. dry wt were prepared as described by Budd \& Harley (1962).

Incubation was at room temperature $\left(22.5\right.$ to $\left.25.5^{\circ}\right)$ with aeration (Budd, 1969a), terminated by rapid filtration on Whatman No. 54 paper circles. After about Io sec. rinsing with glass-distilled water on the filter the mycelium was extracted, usually with $\mathrm{I} \cdot \mathrm{O} \mathrm{N}-\mathrm{HNO}_{3}$, for $24 \mathrm{hr}$ in a centrifuge tube. Mycelium and extractant were then separated by centrifugation, the mycelium extracted with more $\mathrm{I} \cdot \mathrm{O} \mathrm{N}-\mathrm{HNO}_{3}$ and the combined extracts made to known volume with glass-distilled water. In some experiments this procedure was replaced by wet combustion of the sample with I ml. $70 \%$ (w/v) $\mathrm{HNO}_{3}$, followed by dilution to known volume with glass-distilled water. Extraction of sodium and potassium by these two procedures agreed to within $\pm 2 \%$.

Sodium and potassium contents of suitably diluted portions of the mycelial extracts were determined by flame emission spectrophotometry, with a Unicam SP 90 A atomic absorption spectrophotometer in the emission mode. Standard solutions and blanks were adjusted to the same content of nitric acid as the unknown solutions. Mutual interference between sodium and potassium in flame emission analysis was negligible at their relative concentrations in the extracts. Rubidium did interfere with this method of potassium estimation. A correction factor was established by first determining the rubidium concentration of the extract as described below, and then determining the expected error in potassium flame-emission from experimentally prepared curves which related this emission to $\mathrm{Rb}^{+}$and $\mathrm{K}^{+}$concentrations in mixed solution.

Rubidium uptake was determined by using ${ }^{86} \mathrm{Rb}$ as a tracer. The isotope was obtained from the Radiochemical Centre, Amersham, Buckinghamshire, England as an aqueous solution of $\mathrm{RbCl}$; this was diluted immediately before use with carrier $\mathrm{RbCl}$ to approximately $2.5 \mu \mathrm{Ci} / \mathrm{m}$-equiv. $\mathrm{Rb}^{+}$. The amount of isotope in mycelial extracts was determined by liquid scintillation spectrometry with the Packard ' 3002 ' Tri-Carb system and the second solution of Bruno \& Christian (I96I) as liquid fluor. The specific activity of the $\mathrm{RbCl}$ supplied to the mycelium was determined in the same way at the time of assaying the extracts.

Chloride in mycelial extracts was determined by coulometric titration with a BuchlerCotlove automatic chloride titrator. All $\mathrm{pH}$ measurements were made with a Heathkit model EUW-3or recording $\mathrm{pH}$ meter and a Sargent combination electrode.

Ouabain octahydrate was purchased from Sigma Chemical Co., St. Louis, Mo., 
U.S.A. and rubidium chloride from Alfa Inorganics, Inc., Beverly, Mass., U.S.A. All other chemicals were of analytical grade.

\section{RESULTS}

Table $\mathrm{I}$ shows the levels of sodium and potassium in mycelium grown in low- $\mathrm{K}^{+}$ medium and in normal mycelium from $\mathrm{Gl}$ medium. Growth on the low-K $\mathrm{K}^{+}$medium resulted in a significant decrease in potassium content, and an increase in that of sodium. The specific growth rates in the two media were identical for at least $56 \mathrm{hr}$ (to a yield of about $2.5 \mathrm{~g}$. dry matter/1.). It is clear that the levels of $\mathrm{K}^{+}$and $\mathrm{Na}^{+}$could be manipulated within the limits of these experiments without fundamentally changing the metabolic characteristics of the mycelium.

\section{Table I. Sodium and potassium contents of normal and} low-K+ mycelium of Neocosmospora vasinfecta

\begin{tabular}{|c|c|c|c|c|c|c|}
\hline \multirow[b]{2}{*}{ Mycelium } & \multicolumn{3}{|c|}{ Sodium } & \multicolumn{3}{|c|}{ Potassium } \\
\hline & Mean* & $\sigma$ & No. & Mean & $\sigma$ & No. \\
\hline $\begin{array}{l}\text { Normal } \\
\text { Low-K }\end{array}$ & $\begin{array}{r}0.98 \\
26 \cdot 26\end{array}$ & $\begin{array}{l}0.35 \\
9 \cdot 06\end{array}$ & $\begin{array}{r}9 \\
16\end{array}$ & $\begin{array}{l}62 \cdot 08 \\
21 \cdot 70\end{array}$ & $\begin{array}{l}8 \cdot 39 \\
6 \cdot 52\end{array}$ & $\begin{array}{l}12 \\
16\end{array}$ \\
\hline
\end{tabular}

* Values are $\mu$-equiv./100 mg. dry weight. $\sigma=$ Standard deviation. No. $=$ number of experiments. Growth conditions as in text.

On transfer to dilute solutions of potassium salts, the low- $\mathrm{K}^{+}$mycelium took up potassium and lost sodium, reaching new equilibrium levels of both ions after 2 to $3 \mathrm{hr}$. Figure I shows the results of an experiment in which $\mathrm{KCl}$ (O. I $\mathrm{mM}$ ) was the incubation medium. The $\mathrm{pH}$ value was monitored continuously; the changes recorded are characteristic and differed only slightly for more concentrated $\mathrm{KCl}$ solutions. Changes in $\mathrm{pH}$ value of this order had essentially no effect on the net $\mathrm{K}^{+}$uptake (Fig. 2). As shown in Fig. r, potassium uptake and sodium loss were roughly equivalent; after $3 \mathrm{hr}$ $5 \cdot \mathrm{I} \mu$-equiv. $\mathrm{K}^{+}$were absorbed for every $4 \cdot 2 \mu$-equiv. $\mathrm{Na}^{+}$lost. However, results to be presented showed that the $\mathrm{K}^{+}: \mathrm{Na}^{+}$transport ratio had no characteristic value; it was strongly affected by experimental conditions, and was not usually close to unity. It also appears unlikely that deviations of the $\mathrm{K}^{+}: \mathrm{Na}^{+}$ratio from unity were closely related to the amounts of chloride absorbed, because chloride uptake was consistently small during the first hour, the period when the greatest adjustment in $\mathrm{K}^{+}$and $\mathrm{Na}^{+}$ levels took place (Fig. I).

Potassium uptake was essentially complete after $2 \mathrm{hr}$ for $\mathrm{KCl}$ concentrations between $0 \cdot \mathrm{I} \mu \mathrm{M}$ and Io mM. The relationships of $\mathrm{K}^{+}$uptake and $\mathrm{Na}^{+}$loss to $\mathrm{KCl}$ concentration for a $2 \mathrm{hr}$ incubation period are shown (Fig. 3). The total potassium uptake varied somewhat less than twofold over this $10,000-$ fold range of $\mathrm{K}^{+}$concentration, while $\mathrm{Na}^{+}$loss was unaffected.

Glucose $(0.1 \%)$ in the medium had no effect on the uptake of $\mathrm{K}^{+}$or loss of $\mathrm{Na}^{+}$ during 2 hr.

Effects of Inhibitors. Sodium azide and 2,4-dinitrophenol (DNP) strongly decreased the $\mathrm{K}^{+}$level at $2 \mathrm{hr}$ but they had a smaller effect on the time required to reach equilibrium, as shown for sodium azide at I mM in Fig. 4. The effects of DNP concentrations 
are shown in Table 2. The total uptake of $\mathrm{K}^{+}$could be decreased by 70 to $80 \%$ with the proper concentration of inhibitor. On the other hand, $\mathrm{Na}^{+}$loss accompanying $\mathrm{K}^{+}$ uptake was much less sensitive to both inhibitors. Consequently, the $\mathrm{K}^{+}: \mathrm{Na}^{+}$transport ratio fluctuated, e.g. from $2 \cdot 3$ to $\mathrm{I} \cdot \mathrm{O}$ in Table 2 .

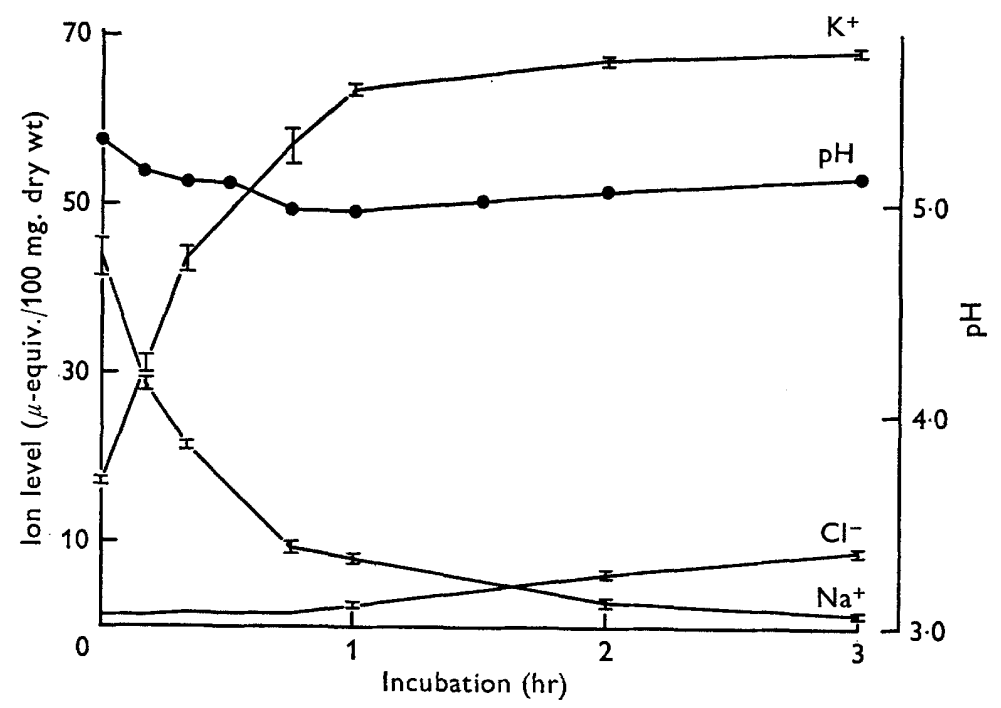

Fig. I. Changes in $N$. vasinfecta mycelial ion levels and in extracellular pH values, during incubation of low- $\mathrm{K}^{+}$mycelium in $0.1 \mathrm{mM} \mathrm{KCl}$ at $25.5^{\circ}$ (The pH values are those measured a sample size of $38 \mathrm{mg}$. dry wt incubated in $\mathrm{I} 1$. $\mathrm{KCl}$.) Bars show range of duplicates.

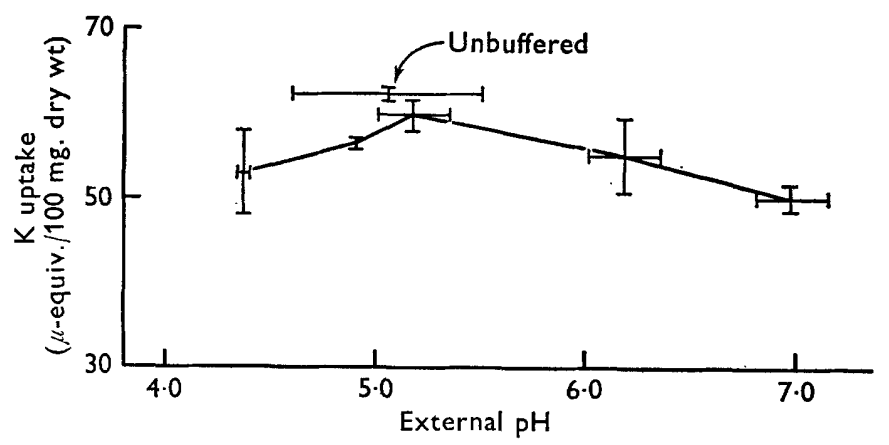

Fig. 2. Effect of $\mathrm{pH}$ value on potassium uptake from $\mathrm{mm}-\mathrm{K}^{+}$by $N$. vasinfecta. Uptake for $2 \mathrm{hr}$ at $23.5^{\circ}$. Buffer system below pH $5.0, \mathrm{KH}$ phthalate $+\mathrm{HCl}$; above $\mathrm{pH} 5.0, \mathrm{KH}_{2} \mathrm{PO}_{4}+$ $\mathrm{KOH}$. Vertical bars show range of duplicates; horizontal bars connect initial and final $\mathrm{pH}$ values.

Ouabain (O. I mM) had no effect on the movement of either $\mathrm{K}^{+}$or $\mathrm{Na}^{+}$when presented simultaneously with the $\mathrm{KCl}$. When the $\mathrm{KCl}$ was presented following pre-incubation I hr with ouabain, a ${ }_{5} \%$ decrease in $\mathrm{K}^{+}$transport and no significant effect on $\mathrm{Na}^{+}$ transport were observed over $2 \mathrm{hr}$.

Effect of other cations. Sodium and magnesium were the major cations in the growth medium used in these experiments. Of these, $\mathrm{Na}^{+}$had no significant effect on the $2 \mathrm{hr}$ 
Table 2. Effect of 2,4-dinitrophenol on $\mathrm{K}^{+}$uptake and $\mathrm{Na}^{+}$ loss by low- $K^{+}$mycelium of Neocosmospora vasinfecta

$\begin{array}{cccc}\text { DNP (M) } & \mathrm{K}^{+} \text {uptake } & \mathrm{Na}+\text { loss } & \begin{array}{c}\mathrm{K}^{+} \text {uptake/ } \\ \mathrm{Na}^{+} \text {loss }\end{array} \\ \text { None (control) } & 48 \cdot 7^{*} & 2 \mathrm{I} \cdot 0^{*} & 2 \cdot 3 \\ 30 \mu_{\mathrm{M}} & 35.8 & 20 \cdot 0 & \mathrm{I} \cdot 8 \\ 100 \mu_{\mathrm{M}} & 16 \cdot 9 & \mathrm{I} 5.4 & \mathrm{I} \cdot \mathrm{I} \\ 300 \mu_{\mathrm{M}} & 8.8 & 8.5 & \mathrm{I} \cdot \mathrm{O}\end{array}$

* Values (averages of duplicates) in $\mu$-equiv./100 mg. dry wt. Incubation for Io min. in DNP (brought to $\mathrm{pH} 5.7$ with $\mathrm{NaOH}$ ) followed by $2 \mathrm{hr}$ incubation in $\mathrm{KC} \mathrm{mM-KCl}$ at $24^{\circ}$.

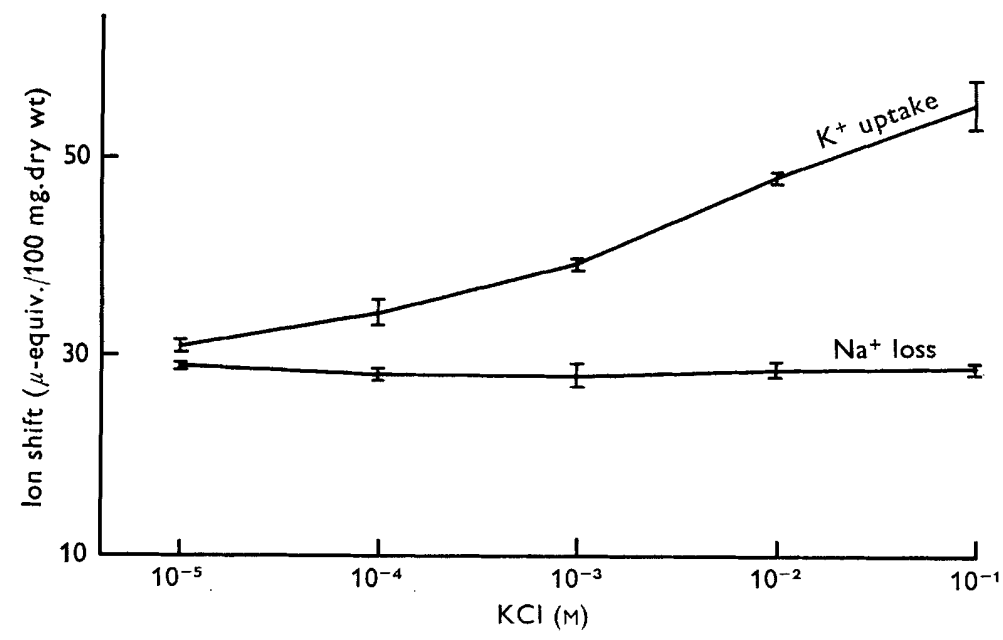

Fig. 3. Effect of $\mathrm{KCl}$ concentration on potassium uptake and sodium loss by $N$. vasinfecta. Uptake for $2 \mathrm{hr}$ at $25^{\circ}$. Bars show range of duplicates.

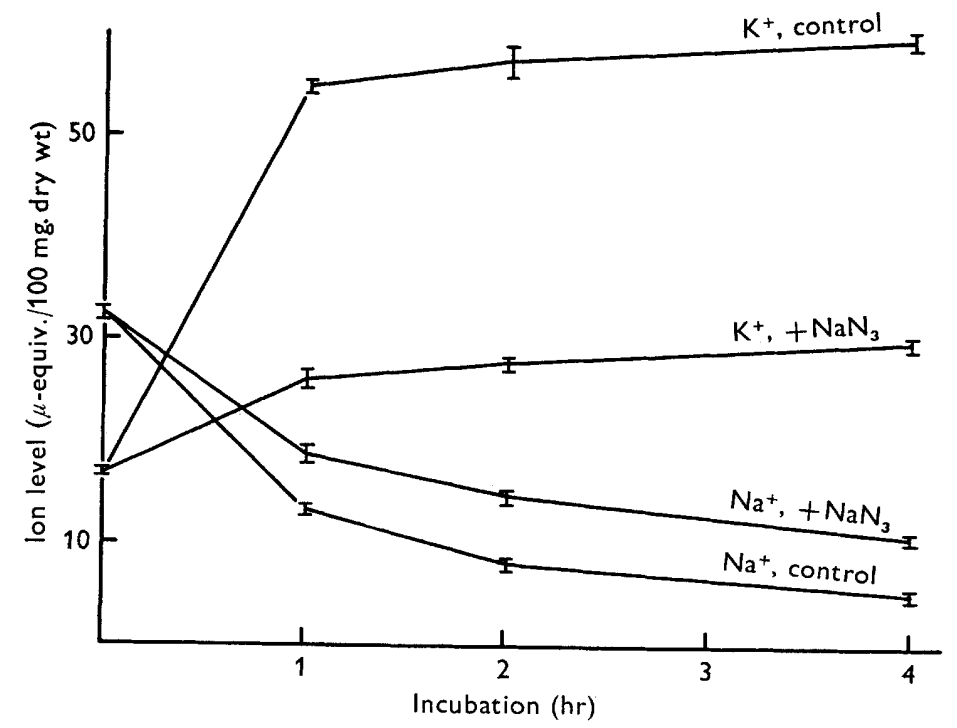

Fig. 4. Effect of mM-sodium azide on potassium uptake and sodium loss at $24.5^{\circ}$. Controls incubated in $\mathrm{mm}-\mathrm{NaCl}$. Bars show range of duplicates. 
$\mathrm{K}^{+}$level at up to a I00-fold equivalent excess over $\mathrm{K}^{+}$in the uptake medium. Net loss of $\mathrm{Na}^{+}$under these conditions was, however, drastically decreased. Magnesium, when provided at Ioo-fold equivalent excess $\left(\mathrm{MgSO}_{4} 50 \mathrm{mM} ; \mathrm{KCl} \mathrm{I} \mathrm{mm}\right)$, did not affect the time required for $\mathrm{K}^{+}$equilibration but depressed the equilibrium $\mathrm{K}^{+}$level. This effect was hyperbolic with $\mathrm{Mg}^{2+}$ concentration and amounted to a $20.0 \%$ decrease in the equilibrium $\mathrm{K}^{+}$level at Ioo-fold equivalent excess of $\mathrm{Mg}^{2+}$. However, there was no effect on simultaneous $\mathrm{Na}^{+}$loss.

Calcium acted similarly to $\mathrm{Mg}^{2+}$ but was more potent. At twofold equivalent excess $\left(\mathrm{CaCl}_{2}\right.$ I mM; $\left.\mathrm{KCl} \mathrm{I} \mathrm{mM}\right), \mathrm{K}^{+}$uptake was decreased $25 \%$ after $2 \mathrm{hr}$ but $\mathrm{Na}^{+}$loss was unaffected.

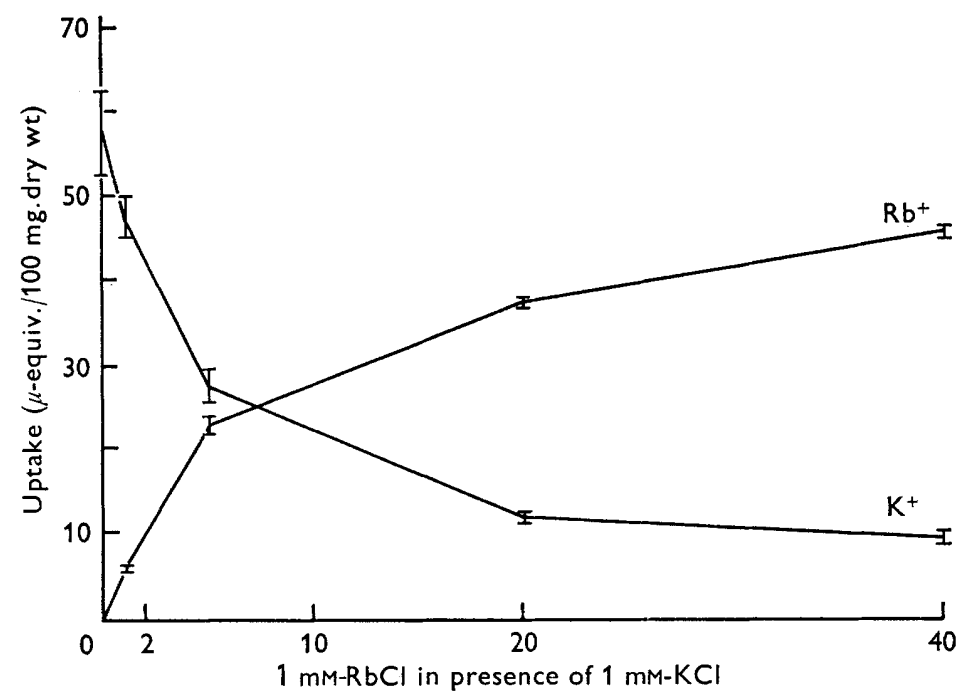

Fig. 5. Effect of various concentrations of $\mathrm{RbCl}$ on uptake of both $\mathrm{Rb}^{+}$and $\mathrm{K}^{+}$from $\mathrm{mM}-\mathrm{KCl}$ by $N$, vasinfecta at $22 \cdot 5^{\circ}$. Bars show range of duplicates.

The effects of various concentrations of rubidium on $\mathrm{K}^{+}$uptake from $\mathrm{mm}-\mathrm{KCl}$ are shown in Fig. 5. As usual, the net $\mathrm{K}^{+}$uptake was essentially complete in $2 \mathrm{hr}$ although $\mathrm{Rb}^{+}$continued to accumulate for at least $4 \mathrm{hr}$. Depression of the equilibrium $\mathrm{K}^{+}$level was hyperbolic with $\mathrm{Rb}^{+}$concentration, and amounted to $50 \%$ at fivefold equivalent excess of rubidium. Depression of the $\mathrm{K}^{+}$level was accompanied by an almost equivalent accumulation of $\mathrm{Rb}^{+}$, although this relationship would certainly be different for a $4 \mathrm{hr}$ incubation period. As in the case of $\mathrm{Mg}^{2+}$ the net $\mathrm{Na}^{+}$loss was unaffected by $\mathrm{Rb}^{+}$in the $\mathrm{KCl}$ solution.

Loss of ions from mycelium. A smaller loss of $\mathrm{Na}^{+}$also occurred when low- $\mathrm{K}^{+}$ mycelium was transferred to distilled water instead of to $\mathrm{KCl}$ solutions; this loss was complete within I hr and amounted to 20 to $25 \%$ of the initial content. Simultaneously a smaller loss of $\mathrm{K}^{+}$sometimes took place, not exceeding $14 \%$ of the initial content.

The characteristics of $\mathrm{K}^{+}$loss by mycelium previously allowed to reach equilibrium in $\mathrm{KCl}$ solutions should indicate how the equilibrium $\mathrm{K}^{+}$level is established and maintained.

(a) $\mathrm{K}^{+}$losses to water only. As with the untreated low- $\mathrm{K}^{+}$mycelium, a small loss of potassium took place, complete within $\mathrm{I} \mathrm{hr}$, when the mycelium was transferred to 
distilled water following equilibration in $\mathrm{KCl}$ (Table 3 ). The actual loss of $\mathrm{K}^{+}$was independent of the volume of washing water over a tenfold range. Also it is clear (lines 2 and 6, Table 3) that, following suspension of the mycelium for $\mathrm{I} \mathrm{hr}$ in one volume of water, no further $\mathrm{K}^{+}$was lost on transfer to a second, identical volume of water. Lines 4 and 6 of Table 5 show that $\mathrm{K}^{+}$loss was not enhanced by mM-NaCl. This was also true for $10 \mathrm{~mm}-\mathrm{NaCl}$ and for $20 \mathrm{~mm}$-sodium phosphate (at $\mathrm{pH} \mathrm{6.5)}$.

Table 3. Loss of potassium to water at $24^{\circ}$ by $N$. vasinfecta following a period of $\mathrm{K}^{+}$uptake (2-hr uptake from $\mathrm{mM}-\mathrm{KCl}$ at $24^{\circ}$ )

$\begin{array}{cccc}\begin{array}{c}\text { Wash volume } \\ \text { (ml.) }\end{array} & \begin{array}{c}\text { Wash time } \\ (\mathrm{hr})\end{array} & \mathrm{K}^{+} \text {level* } & \begin{array}{c}\text { Control } \\ (\%)\end{array} \\ - & - & 69 \cdot 9 \pm 3 \cdot 4 & 100 \cdot 0 \\ 1000 & \mathrm{I} & 65 \cdot 2 \pm \mathrm{I} \cdot 4 & 93 \cdot 3 \\ 1000 & 2 & 64 \cdot 7 \pm 4 \cdot \mathrm{I} & 92 \cdot 6 \\ 2000 & 2 & 64 \cdot 9 \pm 3 \cdot 8 & 92 \cdot 8 \\ 200 & 2 & 63 \cdot 8 \pm 3 \cdot 9 & 91 \cdot 3 \\ 1000+1000 & \mathrm{I}+\mathrm{I} & 64 \cdot 6 \pm 0 \cdot 9 & 92 \cdot 4\end{array}$

${ }^{*} \mathrm{~K}^{+}$levels (mean of triplicates) expressed as $\mu$-equiv./roo mg.dry wt, $\pm \sigma . \mathrm{K}^{+}$level of samples before incubation in $\mathrm{KCl}, 36 \cdot 4 \mu$-equiv./100 mg. dry wt.

Table 4. Potassium loss as influenced by 2,4-dinitrophenol in N. vasinfecta

\begin{tabular}{|c|c|c|c|c|}
\hline \multicolumn{2}{|c|}{ Uptake conditions } & \multicolumn{2}{|c|}{ Washing conditions } & \multirow{3}{*}{$\begin{array}{l}\mathrm{K}^{+} \text {level* } \mu \text {-equiv. } \\
\text { I00 mg. dry wt. }\end{array}$} \\
\hline & & & Incubation & \\
\hline$[\mathrm{KCl}]$ & Additions & Solution & time (hr) & \\
\hline - & - & - & - & 27.5 \\
\hline \multirow[t]{6}{*}{$\mathrm{mm}$} & - & - & - & 67.4 \\
\hline & - & Water & $\mathbf{I}$ & $62 \cdot 2$ \\
\hline & & & 3 & $57 \cdot 8$ \\
\hline & - & $0.3 \mathrm{~mm}-\mathrm{DNP}$ & I & $50 \cdot 3$ \\
\hline & & & 3 & $48 \cdot 9$ \\
\hline & $0.3 \mathrm{~mm}-\mathrm{DNP}$ & - & - & $34 \cdot I$ \\
\hline
\end{tabular}

* $\mathrm{K}^{+}$levels averages of duplicates. $\mathrm{K}^{+}$uptake period, $2 \mathrm{hr}$ at $22 \cdot 5^{\circ}$. (DNP brought to pH $5 \cdot 7$ with $\mathrm{NaOH}$.)

(b) $K^{+}$losses to inhibitor solutions. A comparison of lines I, 2 and 7 of Table 4 shows that DNP at a concentration already shown to inhibit $\mathrm{K}^{+}$uptake by over $70 \%$ (Fig. 4; Table 2), decreased net $\mathrm{K}^{+}$uptake to $16.5 \%$ of the control. The resulting steady $\mathrm{K}^{+}$level was just over half that in control samples. When presented to mycelium immediately following equilibration in $\mathrm{KCl}$, however, the DNP was far less effective in decreasing the steady $\mathrm{K}^{+}$level (cf. Table 4 , lines 3 to 6 ). After $3 \mathrm{hr}$, the $\mathrm{K}^{+}$level in DNP-treated control samples was approximately $85 \%$ of that in watertreated control samples. Similar results were obtained with sodium azide (Table 5). Depending on whether pre-equilibration took place in $\mathrm{KCl} O \cdot \mathrm{I} \mathrm{M}$ or $\mathrm{mm}$ subsequent transfer to sodium azide depressed the $\mathrm{K}^{+}$level to 85 to $9 \mathrm{I} \%$ of $\mathrm{NaCl}$-treated controls (Table 4 , lines 2 to 5 ). In parallel experiments where sodium azide (mM) was presented simultaneously with $\mathrm{KCl}$, the $\mathrm{K}^{+}$level was depressed to less than $50 \%$ of that of the controls, irrespective of incubation period (Fig. 4). Therefore, like DNP, azide was less effective in inducing $\mathrm{K}^{+}$loss than in preventing $\mathrm{K}^{+}$uptake. 
(c) $\mathrm{K}^{+}$losses to $\mathrm{RbCl}$ solutions. Potassium loss to $\mathrm{RbCl}$ Io $\mathrm{mm}$ was compared with the effect of the same $\mathrm{RbCl}$ level on $\mathrm{K}^{+}$uptake from $\mathrm{KCl}$ mM. All samples not postincubated in $\mathrm{RbCl}$ were held in distilled water for the same time. Treatment with $\mathrm{RbCl}$ was more effective than any of the preceding treatments in inducing $\mathrm{K}^{+}$losses from the mycelium (Table 6). Nevertheless, the $\mathrm{K}^{+}$level was not decreased to that of mycelium which had absorbed $\mathrm{K}^{+}$in the presence of $\mathrm{RbCl}$, even after twice as long an exposure to $\mathrm{Rb}^{+}$(line 7 and line 5, Table 6). The loss of potassium was insignificant after the second hour, despite continuing uptake of $\mathrm{Rb}^{+}$. After $4 \mathrm{hr}$, the $\mathrm{Rb}^{+}: \mathrm{K}^{+}$ratio in the post-incubation medium in this experiment exceeded 200 , yet the $\mathrm{K}^{+}$level was not decreased to that found for a $\mathrm{Rb}^{+}: \mathrm{K}^{+}$ratio of $\mathrm{Io}$ in the uptake medium. Therefore, the bulk of mycelial $\mathrm{K}^{+}$was not removed by $\mathrm{Rb}+$ ions.

Table 5. Potassium loss as influenced by sodium azide in N. vasinfecta

$\begin{array}{cccc}\text { Uptake soln. } & \begin{array}{c}\text { Washing soln. } \\ (\mathrm{mM})\end{array} & \mathrm{K}+\text { level } & \mathrm{Na}^{+} \text {level } \\ - & - & \mathrm{I} 8 \cdot \mathrm{I} & 2 \mathrm{I} \cdot \mathrm{I} \\ 0 \cdot \mathrm{IM}-\mathrm{KCl} & \mathrm{NaCl} & 58 \cdot 6 & \mathrm{I} \cdot \cdot 2 \\ & \mathrm{NaN}_{3} & 53 \cdot 3 & \mathrm{II} \cdot 3 \\ \mathrm{mM}-\mathrm{KCl} & \mathrm{NaCl} & 59 \cdot 5 & 6 \cdot \mathrm{I} \\ & \mathrm{NaN}_{3} & 50 \cdot 9 & 8 \cdot 0 \\ & \mathrm{KCl} & 6 \mathrm{I} \cdot 2 & 0 \cdot 6\end{array}$

Ion levels (averages of duplicates) in $\mu$-equiv./100 mg. dry wt. $\mathrm{K}^{+}$uptake, $2 \mathrm{hr}$ at $23.5^{\circ}$. Washing period, $\mathrm{I} \mathrm{hr}$ at $235^{\circ}$.

Table 6. Effect of $\mathrm{RbCl}$ on the equilibrium $\mathrm{K}^{+}$level in $N$. vasinfecta

\begin{tabular}{|c|c|c|c|}
\hline Uptake medium & Washing medium (hr) & $\begin{array}{c}\mathbf{K}^{+} \text {level }{ }^{*} \\
\mu \text {-equiv. }\end{array}$ & $\begin{array}{l}+ \text { level* } \\
\text { dry wt }\end{array}$ \\
\hline- & - & $10 \cdot 08$ & - \\
\hline $\mathrm{mm}-\mathrm{KCl}$ & $\begin{array}{l}\text { Water, } 2 \\
\text { Water, } 4\end{array}$ & $\begin{array}{l}51 \cdot 98 \\
50 \cdot 40\end{array}$ & - \\
\hline $\begin{array}{l}\text { mм-KCl+ } \\
\text { I omm- } \mathrm{RbCl}\end{array}$ & $\begin{array}{l}\text { Water, } 2 \\
\text { Water, } 4\end{array}$ & $\begin{array}{l}20 \cdot 14 \\
20 \cdot 63\end{array}$ & $\begin{array}{l}35 \cdot 44 \\
38 \cdot 75\end{array}$ \\
\hline $\mathrm{mm}-\mathrm{KCl}$ & $\begin{array}{l}\text { Iomm-RbCl, } 2 \\
\text { I omm-RbCl, } 4\end{array}$ & $\begin{array}{l}36 \cdot 97 \\
35 \cdot 13\end{array}$ & $\begin{array}{l}19 \cdot 38 \\
32 \cdot 45\end{array}$ \\
\hline
\end{tabular}

* Ion levels (averages of duplicates) $\mathrm{K}^{+}$uptake for $2 \mathrm{hr}$. Temperature, $23^{\circ}$.

\section{DISCUSSION}

The absorption of $\mathrm{K}^{+}$and of other ions by a variety of organisms leads to an equilibrium condition at which no further net uptake occurs. Equilibrium is reached within minutes or hours in bacteria (Schultz, Epstein \& Solomon, I963; Galdiero, 1966), while for roots of higher plants one or more days may be required (Jackson \& Edwards, 1966). In the present experiments with Neocosmospora vasinfecta approximately $2 \mathrm{hr}$ sufficed, for a wide range of external $\mathrm{K}^{+}$concentrations. In general, and notably for monovalent ions, the equilibrium appears to be dynamic, with efflux balancing influx (Rothstein, 1959). Although no data on simultaneous $\mathrm{K}^{+}$fluxes are as yet available for $N$. vasinfecta, the present work provides some information about efflux from $\mathrm{K}^{+}$ loaded mycelium. Experiments involving washing such mycelium in water or inhibitor 
solutions (Tables 3 to 5 ) indicate that simple diffusive efflux (leakage) is unlikely to play a major role. On the other hand, the effect of $\mathrm{Rb}^{+}$on $\mathrm{K}^{+}$loss (Table 6) is most easily explained as exchange diffusion, in which $\mathrm{K}^{+}$leaves in exchange for $\mathrm{Rb}^{+}$entering the mycelium. The specificity of $\mathrm{K}^{+}$loss towards $\mathrm{Rb}^{+}$and $\mathrm{Na}^{+}$resembles that of $\mathrm{K}^{+}$ uptake, suggesting that the same transport system may be involved in both processes. Equilibria mediated by a $\mathrm{K}^{+}$exchange system are known in other micro-organisms (Epstein \& Schultz, 1966; Slayman \& Tatum, 1965).

Table 6 also shows that a relatively large proportion of mycelial $\mathrm{K}^{+}$appears to be unavailable for exchange with $\mathrm{Rb}^{+}$when the latter is presented after $\mathrm{K}^{+}$uptake is complete. Two explanations suggest themselves, both of which involve a secondary sequestration of $\mathrm{K}^{+}$following its entry into the cell. (I) A fraction of cellular $\mathrm{K}^{+}$may become bound in a non-exchangeable form after its discharge from the potassium transport system. (2) The secondarily sequestered fraction of cell $\mathrm{K}^{+}$may remain exchangeable but be associated with a cytoplasmic system which discriminates more strongly against $\mathrm{Rb}^{+}$than does the potassium transport system itself. A decision between these alternatives cannot be made without recourse to isotopic potassium. Nevertheless, the potassium level in the mycelium does not appear to be regulated solely by the properties of the transport system itself. The penetration of $\mathrm{Rb}^{+}$into Neurospora crassa is apparently followed by its binding into a non-exchangeable form (Lester \& Hechter, 1958).

Whereas the equilibrium $\mathrm{K}^{+}$level appears to be associated with $\mathrm{K}^{+} \leftrightharpoons \mathrm{K}^{+}$exchange, the approach to equilibrium involves exchange of $\mathrm{K}^{+}$with other cations. Loss of $\mathrm{Na}^{+}$ is usually insufficient to balance $\mathrm{K}^{+}$uptake, and little chloride accompanies $\mathrm{K}^{+}$into the cells, at least during the first hour. It is reasonable to suppose that the excess $\mathrm{K}^{+}$ absorbed is balanced by excretion of $\mathrm{H}^{+}$, as in Escherichia coli (Schultz et al. 1963) and in yeast (Conway \& O'Malley, 1946). Where measured, the actual pH decrease during $\mathrm{K}^{+}$uptake exceeds any expected $\mathrm{pH}$ decrease due to such an exchange, but the $\mathrm{pH}$ changes taking place in distilled water only were never observed.

The mechanism mediating $\mathrm{K}^{+} \leftrightharpoons \mathrm{Na}^{+}$exchange is unknown, but the operation of a classical sodium pump is not supported by either the wide fluctuations in the $\mathrm{K}^{+}: \mathrm{Na}^{+}$ transport ratio or the insensitivity to ouabain.

Lack of information on the trans-surface electrical potential difference prevents a final decision whether $\mathrm{K}^{+}$uptake in Neocosmospora vasinfecta is active or not (Ussing, 1949). Values of this potential difference have been reported for Neurospora crassa which will account for a I0,000-fold accumulation of $\mathrm{K}^{+}$in cells as compared with external medium, without invoking active transport (Slayman, 1965a). However, the effects of sodium azide and 2,4-dinitrophenol on $\mathrm{K}^{+}$uptake (Table 2; Fig. 4) strongly indicate the participation of energy metabolism in this process. These inhibitors do not act merely by rendering the cellular membranes leaky (Tables 4, 5; Slayman \& Tatum, 1964). Two other modes of action are possible: (a) that potassium influx depends, at least partly, on energy transfer; or $(b)$ that the trans-surface electrical potential difference is made less negative. If the $\mathrm{K}^{+}$transport system is electrogenic, as Slayman ( $1965 b$ ) has concluded for $N$. crassa, then it may be impossible to distinguish between these alternatives. For the present, it is sufficient to conclude that $\mathrm{K}^{+}$uptake is a metabolic process, although it may not qualify as active transport.

A detailed comparison of the $\mathrm{K}^{+}$transport in Neocosmospora vasinfecta with that of other fungi is not possible on the basis of the present studies. The use of low- $\mathrm{K}^{+}$ 
mycelium in these experiments is analogous to the production of sodium-yeast (Conway \& Moore, I954). In the importance of ion-exchange processes to net $\mathrm{K}^{+}$uptake and maintenance of the equilibrium $\mathrm{K}^{+}$level, and in the sensitivity of $\mathrm{K}^{+}$uptake to alterations of cellular energy metabolism $N$. vasinfecta shows a general similarity to other fungi (Rothstein, I959; Slayman \& Tatum, I964, 1965). Discrimination between $\mathrm{K}^{+}$and $\mathrm{Na}^{+}$by the $\mathrm{K}^{+}$-uptake system appears to be greater in $N$. vasinfecta than in yeast (Conway \& Duggan, 1958). Measurements of potassium fluxes are a clearly desirable next phase in these studies.

This work was supported by a grant-in-aid of research provided by the Ontario Department of University Affairs.

\section{REFERENCES}

Bruno, G. A. \& Christian, J. E. (196I). Determination of carbon-14 in aqueous bicarbonate solutions by liquid scintillation counting technique. Analyt. Chem. 33, 1216.

BuDd, K. (1969a). The assimilation of bicarbonate by Neocosmospora vasinfecta. Can. J. Microbiol. 15 , 389.

BUDD, K. $(1969 b)$. Net transport of potassium by nongrowing fungal mycelium. XI Intern. Botan. Congr. Proceedings. (In Press.)

BUDD, K. \& HARLEY, J. L. (I962). The uptake and assimilation of ammonia by Neocosmospora vasinfecta. New Phytol. 6r, 138.

Conway, E. J. \& Duggan, F. (1958). A cation carrier in the yeast cell wall. Biochem. J. 69, 265.

Conway, E. J. \& O'MALleY, E. (1946). The nature of the cation changes during yeast fermentation, with formation of $0.02 N$ hydrogen ion. Biochem. J. 40, 59.

Conway, E. J. \& Moore, P. T. (I954). A sodium-yeast and some of its properties. Biochem. J. 57, 523.

Epstern, W. \& SchuLTZ, S. G. (1966). Cation transport in Escherichia coli. VI. K exchange. J. gen. Physiol. 49, 469.

GaldIERo, F. (I966). The kinetics of potassium exchange in cells of Staphylococcus aureus. Biochim. biophys. Acta 126, 54 .

Horowitz, N. H. \& Beadle, G. W. (1943). A microbiological method for the determination of choline by use of a mutant of Neurospora. J. biol. Chem. 150, 325.

JACKSON, P. C. \& EDWARDS, D. G. (I966). Cation effects on chloride fluxes and accumulation levels in barley roots. J. gen. Physiol. 50, 225.

LESTER, G. \& HECHTER, O. (1958). Dissociation of rubidium uptake by Neurospora crassa into entry and binding phases. Proc. natn. Acad. Sci. U.S.A. 44, II4I.

Rothstein, A. (1959). Role of the cell membrane in the metabolism of inorganic electrolytes by microorganisms. Bact. Rev. 23, 175.

Rothstern, A. (1965). The Fungi: an Advanced Treatise. Ed. by G. C. Ainsworth and A. S. Sussman, vol. I, p. 429. New York: Academic Press, Inc.

Schultz, S. G., Epstein, W. \& Solomon, A. K. (1963). Cation transport in Escherichia coli. IV. Kinetics of net K uptake. J. gen. Physiol. 47, 329.

SLAYMAN, C. L. (1965a). Electrical properties of Neurospora crassa. Effects of external cations on the intracellular potential. J. gen. Physiol. 49, 69.

Slayman, C. L. (1965b). Electrical properties of Neurospora crassa. Respiration and the intracellular potential. J. gen. Physiol. 49, 93.

Slayman, C. W. \& Tatum, E. L. (1964). Potassium transport in Neurospora. I. Intracellular sodium and potassium concentrations and cation requirements for growth. Biochim. biophys. Acta 88, 578 .

Slayman, C. W. \& Tatum, E. L. (1965). Potassium transport in Neurospora. II. Measurement of steady-state potassium fluxes. Biochim. biophys. Acta 102, I49.

Ussing, H. H. (I949). The distinction by means of tracers between active transport and diffusion. Acta physiol. scand. 19, 43. 